\title{
Use of Sodium-Glucose Co-Transporter-2 Inhibitors in Type 1 Diabetics: Are the Benefits Worth the Risks?
}

Tehreem Fatima ${ }^{1}$, Surik Sedrakyan ${ }^{1}$, Muhammad R. Awan ${ }^{1}$, Mst. Khaleda Khatun ${ }^{1}$, Dibyata Rana 1 , Nusrat Jahan ${ }^{1}$

1. Internal Medicine, California Institute of Behavioral Neurosciences \& Psychology, Fairfield, USA

Corresponding author: Tehreem Fatima, tehreem94@outlook.com

\begin{abstract}
The mainstay of treatment for type 1 diabetes is insulin. The use of insulin for tight glycemic control is the key to preventing micro- and macrovascular complications, but it can also lead to hypoglycemic episodes. Therefore, there is a need for the introduction of a drug that can maintain glucose levels within a safe range without increasing the risk of hypoglycemia. For this reason, SGLT2 (sodium-glucose co-transporter-2) inhibitors has been a hot topic in the last couple of years. They have been proved very efficient in treating type 2 diabetes. Many trials on the safety and efficacy of SGLT2 inhibitors have been done on type 1 diabetics. Some other studies have also been done that prove their benefits in increasing arterial efficacy and reducing GFR (glomerular filtration rate). This review article discusses the benefits and risks. The literature search was performed using PubMed, and after applying the inclusion and exclusion criteria, 16 published papers were found. All relevant articles on the topic have been included. Our review has shown that the benefits of SGLT2 inhibitors outweigh their risks. Their benefits include good glycemic control, HBA1c (glycated haemoglobin) reduction, weight loss, and blood pressure improvement. Furthermore, improvement in GFR and arterial efficacy is also significant. Side effects such as UTI (urinary tract infection) and genital infection have been observed, but their incidence is low. However, DKA (diabetic ketoacidosis) and hypoglycemia are severe side effects that should be highlighted. Hypoglycemia can be prevented by strictly monitoring blood sugar levels. The patient must be educated and counseled about DKA and its symptoms. This will ensure the safety of the patient as euglycemic DKA can prove fatal if not diagnosed earlier. So, SGLT2 inhibitors can be used as an effective drug to control blood sugar levels in type 1 diabetes, especially in patients with a BMI higher than 30. It will not only achieve the treatment goals but can also decrease the morbidity and mortality of the patients. However, more studies need to be done to fully understand DKA caused by SGLT2 inhibitors.
\end{abstract}

Received 07/25/2020

Review began 08/03/2020 Review ended 08/27/2020 Published 08/27/2020

() Copyright 2020 Fatima et al. This is an open access article distributed under the terms of the Creative Commons Attribution License CC-BY 4.0., which permits unrestricted use, distribution, and reproduction in any medium, provided the original author and source are credited.
Categories: Endocrinology/Diabetes/Metabolism, Internal Medicine

Keywords: diabetes mellitus type 1, sodium-glucose co-transporter 2 inhibitor, diabetes type 1

\section{Introduction And Background}

According to 2019 statistics, type 1 diabetes mellitus accounts for five to ten percent of cases of diabetes in the United States, Canada, and Europe [1]. Worldwide, around 1.1 million children and adolescents suffer from type 1 diabetes. Type 1 diabetes is primarily caused by a lack of insulin production while type 2 diabetes mellitus (T2DM) is characterized by the resistance of body tissues to insulin. About $75 \%$ of people do not achieve the required glycemic control of HBA1c (glycated hemoglobin) $=7 \%$, as recommended by the American Diabetes Association [2]. The mainstay of treatment of type 1 diabetes is lifestyle modification, which includes a change in diet and increased physical activity along with insulin replacement [3]. Achieving the required glycemic control is vital because failing to do so might lead to multiple complications such as micro- and macrovascular changes. On the other hand, tight glycemic control may give rise to hypoglycemic episodes, which result in cardiovascular complications in the long run [4]. Hence, a drug that can both control the blood sugar levels and eliminate the risk of hypoglycemia is crucial in the management of type 1 diabetes.

Several drugs have been studied over the past decade that can help to achieve this goal. One such drug is SGLT2 (sodium-glucose co-transporter-2) inhibitors, previously used effectively for type 2 diabetes and known to have a cardio-protective role in T2DM [5]. SGLT2 inhibitor acts by antagonizing SGLT2 receptors in the proximal tubule of the kidney, which is involved in the reabsorption of filtered glucose. This results in promoting renal excretion of glucose, thereby lowering elevated glucose levels [6]. This mechanism helps regulate the patient's blood sugar levels while simultaneously preventing hypoglycemia. Moreover, they can improve HBA1c and body weight among these patients [7]. However, there are several adverse effects, such as euglycemic DKA (diabetic ketoacidosis), UTI (urinary tract infection), genital infections, and AKI (acute kidney injury) [8]. The efficacy and safety of SGLT2 inhibitors in type 1 diabetics have been studied previously, but a comparison of all the risks and benefits of SGLT2 inhibitors and critical analysis on these have not been done. 
This literature review aims to discuss the advantages and disadvantages of SGLT2 inhibitors in type 1 diabetes and to review whether benefits outweigh the risks. The most important aspect of this research is to analyze how beneficial it is to improve HBA1c at the expense of euglycemic DKA. We have critically analyzed this group of medications as these can be a groundbreaking addition to the typical regimen of insulin-only treatment for type 1 diabetes patients, especially for those with uncontrolled diabetes.

\section{Review}

\section{Method}

Literature was searched on PubMed. MeSH keywords used were "Diabetes Mellitus, Type 1" AND "SodiumGlucose Transporter 2 Inhibitors". Studies were selected after applying the following inclusion/exclusion criteria.

The inclusion criteria were: 1) human subjects; 2) paper published in the English language; 3) study types that are clinical trials, observational studies, cohort studies, case-control studies, case reports, and systematic review; and 4) only meta-analysis and systematic review with full articles to be included.

The exclusion criteria were: 1) animal studies and 2) non-English literature.

\section{Results}

After applying the MeSH keywords "Diabetes Mellitus, Type 1" and "Sodium-Glucose Transporter 2 Inhibitors" a total of 97 articles were obtained. Of these articles, about 50 were removed as they were not specifying the disease and drug of interest. On secondary screening, further 31 articles were removed which consisted of book chapters, letters to the editor, review articles, and duplicates. The remaining 16 articles were used for our review article. The total number of participants in our study were 5,256.

\section{Discussion}

In this current review, we analyzed data from 5,256 patients with type 1 diabetes who used SGLT2 inhibitors, to look more closely at the risks and benefits of this drug in type 1 diabetes. For this reason, we have tried not only to include clinical trials on type 1 diabetes but also trials illustrating benefits, e.g., glomerular hyperfiltration and arterial efficacy, and case reports highlighting side effects, e.g., DKA, Fanconi Syndrome. These are summarized in Table 1. 


\section{Cureus}

\begin{tabular}{|c|c|c|c|c|}
\hline $\begin{array}{l}\text { Study/ } \\
\text { reference }\end{array}$ & $\begin{array}{l}\text { Subjects } \\
\text { (N) }\end{array}$ & $\begin{array}{l}\text { Study } \\
\text { design }\end{array}$ & Study duration & Intervention \\
\hline $\begin{array}{l}\text { Mudaliar et al., } \\
2012[9]\end{array}$ & 10 & RCT & $\begin{array}{l}\text { Each participant in five treatment periods } \\
\text { separated by five to } 35 \text { days }\end{array}$ & $\begin{array}{l}\text { Remogliflozin Etobonate } 50 \mathrm{mg}, 150 \mathrm{mg} \text {, } \\
500 \mathrm{mg} \text {, placebo, prandial insulin }\end{array}$ \\
\hline $\begin{array}{l}\text { Parkins et al., } \\
2014[10]\end{array}$ & 40 & RCT & 8 weeks & Empagliflozin 25mg \\
\hline $\begin{array}{l}\text { Henry et al., } \\
2015 \text { [11] }\end{array}$ & 70 & RCT & 2 weeks & Dapagliflozin $2.5 \mathrm{mg}, 5 \mathrm{mg}, 10 \mathrm{mg}$, placebo \\
\hline $\begin{array}{l}\text { Pleber et al., } \\
2015 \text { [12] }\end{array}$ & 75 & RCT & 4 weeks & Empagliflozin $2.5 \mathrm{mg}, 10 \mathrm{mg}, 25 \mathrm{mg}$, placebo \\
\hline $\begin{array}{l}\text { Tomez et al., } \\
2015 \text { [13] }\end{array}$ & 12 & $\begin{array}{l}\text { Before- } \\
\text { after study }\end{array}$ & 24 weeks & Dapagliflozin 10mg \\
\hline $\begin{array}{l}\text { Henry et al., } \\
2015 \text { [14] }\end{array}$ & 35 & RCT & 18 weeks & Canagliflozin $100 \mathrm{mg}, 300 \mathrm{mg}$ \\
\hline $\begin{array}{l}\text { Dandona et al., } \\
2018 \text { [15] }\end{array}$ & 833 & RCT & 52 weeks & Dapagliflozin 5mg, 10mg \\
\hline $\begin{array}{l}\text { Kaku et al., } \\
2019 \text { [16] }\end{array}$ & 40 & RCT & 2 weeks & Ipragliflozin 25mg, 50mg, 100mg \\
\hline $\begin{array}{l}\text { Musso et al., } \\
2019[17]\end{array}$ & 3238 & $\begin{array}{l}\text { Meta- } \\
\text { analysis }\end{array}$ & NA & Sotagliflozin \\
\hline $\begin{array}{l}\text { Mathieu et al., } \\
2020 \text { [18] }\end{array}$ & 813 & RCT & 52 weeks & Dapagliflozin 5mg, 10mg \\
\hline \multicolumn{5}{|l|}{ Benefits } \\
\hline \multicolumn{5}{|l|}{ Arterial function } \\
\hline $\begin{array}{l}\text { Lunder et al., } \\
2018 \text { [19] }\end{array}$ & 40 & RCT & 12 weeks & Empagliflozin \\
\hline \multicolumn{5}{|c|}{ Glomerular hyperfiltration } \\
\hline $\begin{array}{l}\text { Cherney et al. } \\
\text { [20] }\end{array}$ & 40 & RCT & & Empagliflozin 25mg \\
\hline \multicolumn{5}{|l|}{ Risks } \\
\hline \multicolumn{5}{|l|}{ DKA } \\
\hline $\begin{array}{l}\text { Peters et al., } \\
2015 \text { [21] }\end{array}$ & 7 & $\begin{array}{l}\text { Case- } \\
\text { series }\end{array}$ & NA & SGLT2 inhibitors \\
\hline $\begin{array}{l}\text { Tahir et al., } \\
2015 \text { [22] }\end{array}$ & 1 & $\begin{array}{l}\text { Case- } \\
\text { report }\end{array}$ & NA & SGLT2 inhibitors \\
\hline $\begin{array}{l}\text { Markey et al, } \\
2018 \text { [23] }\end{array}$ & 1 & $\begin{array}{l}\text { Case- } \\
\text { report }\end{array}$ & NA & SGLT2 inhibitors \\
\hline \multicolumn{5}{|c|}{ Fanconi syndrome } \\
\hline $\begin{array}{l}\text { Khan et al., } \\
2019 \text { [24] }\end{array}$ & 1 & $\begin{array}{l}\text { Case- } \\
\text { report }\end{array}$ & NA & Canagliflozin \\
\hline
\end{tabular}

TABLE 1: Table illustrating the baseline characteristics of the trials used in the review article DKA: diabetic ketoacidosis

Randomized control trials: safety and efficacy of SGLT2 inhibitors in type 1 diabetics 


\section{Cureus}

Glycemic Benefits of SGLT2 Inhibitors

Researchers of randomized control trials (RCT), established some endpoints to assess the glycemic benefits of SGLT2 inhibitors. They were glucose efficacy parameters and HBA1c levels.

Glucose efficacy: Almost all the trials reported glucose efficacy parameters by using fasting blood glucose (FBG) as mentioned in Figure 1. In all trials, the use of SGLT2 inhibitors was associated with a modest decrease in glucose levels. The most significant drop was observed in 100mg Ipragliflozin, where the adjusted mean difference to placebo was $74 \mathrm{mg} / \mathrm{dl}$, but this trial was done for two weeks [16].

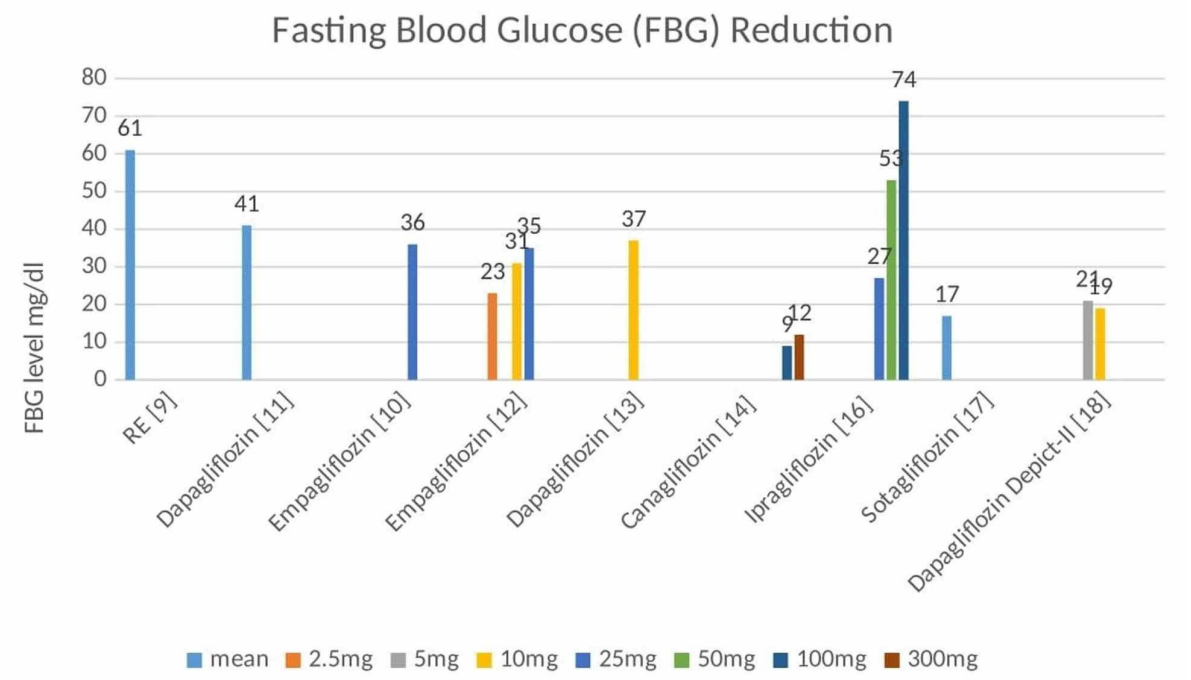

\section{FIGURE 1: Fasting blood glucose level reduction as seen in all} randomized control trials

All values were adjusted according to placebo and baseline values. All values are FBG, except for RE [9], which is reduced incremental adjusted weighted mean glucose, and for dapagliflozin [11], which is 24-h daily average blood glucose.

HBA1c levels: Similarly, most of the studies mentioned HBA1c. All studies showed a drop in their levels as seen in Figure 2. The most significant finding was seen with dapagliflozin 10mg, which showed a drop of about $1.13 \%$ as compared to placebo [13]. Some studies didn't mention HBA1c and used glucose control as the primary means of determining the endpoint. HBA1c is one of the most important factors in determining blood glucose control. Reduction in HBA1c for a longer period of time means fewer chances of microvascular and macrovascular complications [25].

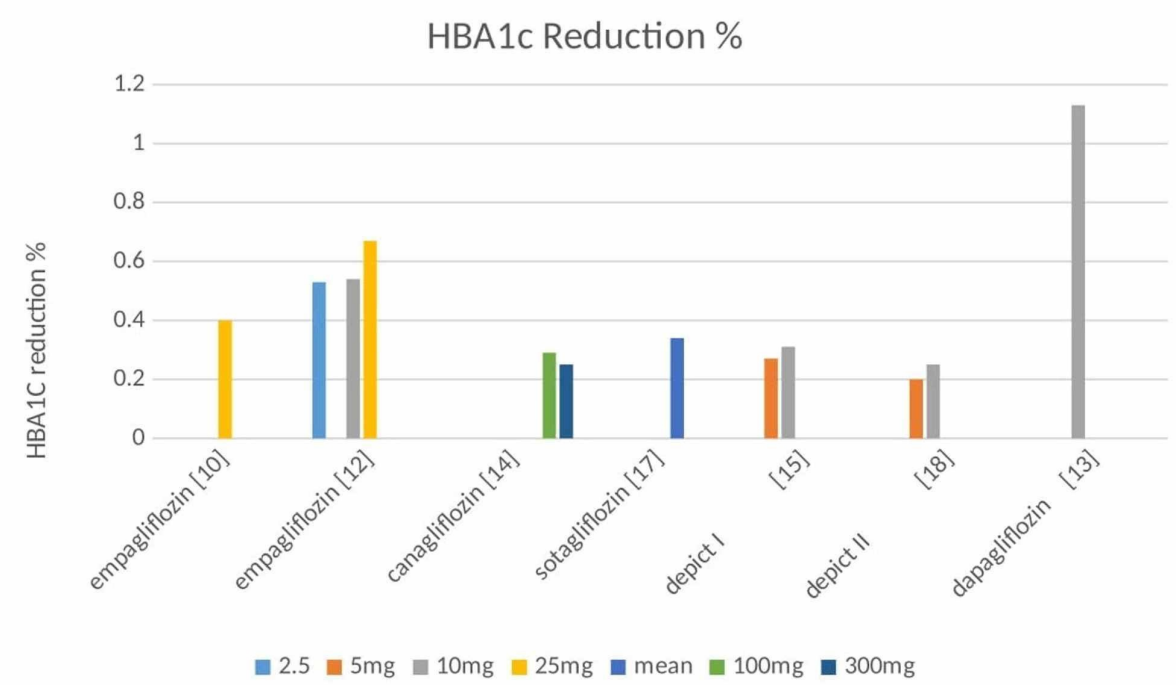

FIGURE 2: HBA1c reduction as seen in all randomized control trials 


\section{Cureus}

Non-glycemic Benefits of SGLT2 Inhibitors

In addition to the beneficial effects related to improved glycemic control, SGLT2 inhibitors have several nonglycemic benefits, such as weight loss, insulin dose reduction, positive effect on blood pressure, increasing arterial efficacy, and a possible reno-protective effect.

Weight loss: Weight gain is a major problem for type 1 diabetics as insulin, which is the mainstay of treatment, causes weight gain. The effect of SGLT2 inhibitors on weight was explored in five studies. Weight reduction was seen in patients as shown in Table 2. The most significant finding was a decrease of up to $5 \%$ as compared to placebo [18]. Weight loss can be attributed to the loss of calories in the urine.

Study/ reference
Parkins et al., 2014 [10]
Henry et al., 2015 [11]
Pleber et al., 2015 [12]
Henry et al., 2015 [14]
Dandona et al., 2018 (DEPICT-
I) [15]
Kaku et al., 2019 [16]
Musso et al., 2019 [17]
Mathieu et al., 2020 (DEPICT-II)
[18]

Mean adjusted insulin dose reduction from baseline* $^{*}$

9 units

$-16.2 \%$

-0.07 to $-0.09 \mathrm{U} / \mathrm{kg}$

$100 \mathrm{mg}$

$9 \%$

$300 \mathrm{mg}$

$13 \%$

Reduction more for $10 \mathrm{mg}$ than $5 \mathrm{mg}$

$25 \mathrm{mg} \quad 14 \%$

$50 \mathrm{mg}$

$18 \%$

$100 \mathrm{mg}$

$19 \%$

$9 \%$
$3.54 \%$

$5 \mathrm{mg}$

$4.42 \%$

$10 \mathrm{mg}$

Mean adjusted bodyweight reduction from baseline ${ }^{\star *}$

$2.6 \mathrm{~kg}$

NA

1.5 to $1.6 \mathrm{~kg}$

NA

$5 \mathrm{mg}$

$2.95 \%$

$10 \mathrm{mg}$

$4.54 \%$

$5 \%$

\section{TABLE 2: Insulin use reduction and weight reduction with the use of SGLT2 inhibitors}

* Mean adjusted insulin dose reduction from baseline compared with placebo. Values are in \%, IU, and mg as given in the original study.

** Bodyweight reduction is adjusted from baseline and placebo. Except for 417 ; which mentioned average weight decreased. Values are in $\%$ and kg.

Insulin dose reduction: Insulin dose reduction was reported by seven studies in the dataset. All showed a significant reduction in insulin dose. Few studies reported mean change in insulin dose from, placebo while others mentioned mean change from the baseline. Nevertheless, the use of SGLT2 inhibitors was associated with a reduction in insulin dose as shown in Table 2.

Effects on blood pressure: Reduction in systolic blood pressure, which could be very beneficial for hypertensive patients. Only, two studies mentioned changes in blood pressure. A meta-analysis of sotagliflozin [17] mentioned a 4mm Hg drop, while the DEPICT-II trial observed an average $3 \mathrm{~mm} \mathrm{Hg}$ reduction with $5 \mathrm{mg}$ and $7 \mathrm{~mm}$ Hg with $10 \mathrm{mg}$ dapagliflozin [18].

\section{Side Effects}

These trials not only assessed the benefits of SGLT2 inhibitors in type 1 diabetic patients but also looked closely at the safety profile. The adverse effects of SGLT2 inhibitors are summarized in Table 3. 


\section{Cureus}

\begin{tabular}{|c|c|c|c|}
\hline Dose /mg & Genital infections (\%) & Severe hypoglycemia (number of events )* & Urinary tract infections $(\%)$ \\
\hline \multicolumn{4}{|c|}{ Henry et al., 2015 [11\} dapagliflozin } \\
\hline 1 & 7.7 & 0 & 0 \\
\hline 2.5 & 0 & 0 & 6.7 \\
\hline 5 & 7.1 & 0 & 0 \\
\hline 10 & 0 & 0 & 0 \\
\hline Placebo & 0 & $6.7 \%^{\star \star}$ & 7.7 \\
\hline \multicolumn{4}{|c|}{ Pleber et al., 2015 [12] empagliflozin } \\
\hline 2.5 & & $0.9^{\star \star \star}$ & \multirow{4}{*}{ NA } \\
\hline 10 & & $1.1^{\star \star \star}$ & \\
\hline 25 & & $1.2^{\star \star \star}$ & \\
\hline Placebo & & $0.9^{\star \star \star}$ & \\
\hline \multicolumn{4}{|c|}{ Henry et al., 2015 [14] canagliflozin } \\
\hline 100 & 9 & 8 & 5 \\
\hline 300 & 2 & 3 & 4 \\
\hline Placebo & 3 & 2 & 2 \\
\hline \multicolumn{4}{|c|}{ Dandona et al., 2018 [15] (DEPICT-I) dapagliflozin } \\
\hline 5 & 16 & 46 & 12 \\
\hline 10 & 14 & 58 & 5 \\
\hline Placebo & 3 & 85 & 8 \\
\hline \multicolumn{4}{|c|}{ Musso et al., 2019 [17] } \\
\hline Sotagliflozin & 3.12 times more risk & Lower risk of hypoglycemia than placebo ( $31 \%)$ & No relationship found \\
\hline \multicolumn{4}{|c|}{ Mathieu et al., 2020 [18] (DEPICT-II) dapagliflozin } \\
\hline $5 \mathrm{mg}$ & 11 & 97 & 9.2 \\
\hline $10 \mathrm{mg}$ & 10 & 84 & 5.2 \\
\hline Placebo & 4 & 65 & 18 \\
\hline
\end{tabular}

\section{TABLE 3: Summary of selected safety outcomes in clinical trials of SGLT2 inhibitors with type 1}

diabetes.

* Inability to perform daily activities

${ }^{\star *}$ Hypoglycemia value in \%

${ }^{\star * \star}$ Rates of severe hypoglycemic episodes per 30 days

Most of the studies mentioned hypoglycemia, genital infections, DKA, and UTI as the most common adverse effects. Some studies also observed renal failure and fractures. Overall, risks were modest and welltolerated.

Hypoglycemia: Most common side effect was hypoglycemia. Mild to moderate hypoglycemia was very common. Only some severe hypoglycemia cases were observed, as mentioned in Table 3. A meta-analysis of the sotagliflozin [17] and DEPICT-I [15] trial showed an interesting finding. The overall risk of hypoglycemia was less than that of a placebo, with a 31\% lower risk of severe hypoglycemia in sotagliflozin. However, all other studies noticed a slight increase in the episodes of hypoglycemia with SGLT2 inhibitors as compared to placebo. 


\section{Cureus}

Infections: SGLT2 inhibitors have not shown a consistent effect on the risk of developing urinary tract infection. In most of the cases, the risk of UTI was higher with placebo. However, there seems to be a relationship between genital infections and SGLT2 inhibitors. In all trials, the incidence was greater with SGLT2 inhibitors.

Diabetic ketoacidosis: The incidence of DKA with SGLT2 inhibitors is uncommon and has a slightly different clinical presentation than the usual DKA. Most cases of DKA are either due to insulin pump failure or missed insulin dose, but some were due to acute infection. If these identified risk factors are dealt within time, the risk of DKA can be further optimized. Studies have shown that approximately $32 \%$ of patients have vomiting problems and that around $35 \%$ of people also have glucose levels below $200 \mathrm{mg} / \mathrm{dl}$, although one of the diagnostic criteria for DKA is glucose levels above $250 \mathrm{mg} / \mathrm{dl}$ [26]. Hence, blood sugar levels below 250 in patients with DKA can delay the diagnosis and the proper treatment of the patients.

Multiple studies of SGLT2 inhibitors linked to DKA have been performed. A review article concluded outcomes of eight RCTs which showed that the mean proportion of SGLT2 inhibitor-associated DKA in the placebo group was $0.59 \%$ compared to $3.48 \%$ and $3.64 \%$ respectively in low-dose and high-dose SGLT2 inhibitors [27]. A meta-analysis carried out in 2017 showed that the incidence of SGLT2 inhibitor-associated DKA was less than 1/1000 in randomized controlled trials and 1.6/1000 person-years in cohort studies [26]. Three out of 10 studies in our data reported on euglycemic or hyperglycemic DKA [10, 14, 17]. Most cases had hyperglycemia, but up to $40 \%$ had euglycemia. Patients improved with proper treatment in all studies and no complications were observed. No mortality was reported in any of the studies. Findings are explained in Table 4.

\begin{tabular}{|c|c|c|c|c|}
\hline Study/ reference & $\begin{array}{l}\text { Subjects } \\
\text { (N) }\end{array}$ & $\begin{array}{l}\text { DKA } \\
\text { (N) }\end{array}$ & Cause & $\begin{array}{l}\text { Percentage of euglycemic and } \\
\text { hyperglycemic DKA }\end{array}$ \\
\hline Parkins et al., 2014 [10] & 40 & 2 & Severe gastroenteritis and insulin pump failure & $\begin{array}{l}\text { Hyperglycemic: } 50 \% \text { Euglycemic: } \\
50 \%\end{array}$ \\
\hline Henry et al., 2015 [14] & 35 & 18 & $\begin{array}{l}\text { Flu, pneumonia, insulin pump failure or malfunction, } \\
\text { inappropriate insulin use }\end{array}$ & $\begin{array}{l}\text { Hyperglycemic: } 60 \% \\
\text { Euglycemic: } 40 \%\end{array}$ \\
\hline $\begin{array}{l}\text { Dandona et al., } 2018 \\
\text { DEPICT-I [15] }\end{array}$ & 833 & 27 & Insulin dose and insulin pump failure & \\
\hline Kaku et al., 2019 [16] & 40 & 4 & $\begin{array}{l}\text { Blood ketone body increases were mild and did not } \\
\text { include ketoacidosis }\end{array}$ & \\
\hline Musso et al., 2019 [1/] & 3238 & $6 r$ & & $\begin{array}{l}\text { Hyperglycemic: } 70 \% \text { Euglycemic: } \\
30 \%\end{array}$ \\
\hline $\begin{array}{l}\text { Mathieu et al., 2020, } \\
\text { DEPICT-II [18] }\end{array}$ & 813 & 21 & ulin pump fallure or missed insulin dose & \\
\hline
\end{tabular}

TABLE 4: Summary of DKA as seen in clinical trials: incidence, probable cause, and percentage of euglycemic and hyperglycemic cases

DKA: diabetic ketoacidosis

Effect of SGLT2 Inhibitors on Arterial Efficacy

Diabetics are more prone to major adverse cardiovascular effects (MACE). Therefore, a study was done to assess the effect of SGLT2 inhibitor empagliflozin on endothelial dysfunction and arterial stiffness, which are good predictors of MACE.

Endothelial function assessment was done by brachial artery flow-mediated dilation (FMD) and reactive hyperemia index (RHI). On the other hand, arterial stiffness was assessed by carotid pulse wave velocity (cPWV), $\beta$-stiffness assessment, and carotid-femoral pulse wave velocity (cfPWV). The trial was done on 40 patients for 12 weeks. The results showed a marked improvement in all assessments [19].

For endothelial dysfunction, FMD showed improvement up to 2.2-fold and RHI improved up to 1.3 -fold. On the other hand, arterial stiffness also showed marked improvement, $\mathrm{CPWV}, \beta$-stiffness assessment improved $14.3 \%$, and cfPWV 3.5 -fold as compared to placebo respectively. Endothelial function and arterial stiffness improvement are of substantial importance because they can lead to an improvement in cardiovascular risk. 
Raised intraglomerular pressure results in hyperfiltration. It is a common complication of diabetes and can eventually lead to diabetic nephropathy. To see the effects of SGLT2 inhibitors on hyperfiltration, multiple studies have been conducted on drugs like empagliflozin [20] and sotagliflozin [17].

A clinical trial conducted to see the effect of empagliflozin on kidney function was done on 40 subjects for eight weeks. It has shown a decrease in GFR (glomerular filtration rate) by $33 \mathrm{~mL} / \mathrm{min} / 1.73 \mathrm{~m}^{2}$ during clamped euglycemia. Similarly, a significant decrease in GFR was observed during clamped hyperglycemia. A modified glucose clamp technique was used in this trial to maintain euglycemic conditions for six hours, followed by hyperglycemic conditions for six hours the next day. This study concluded that short-term treatment with empagliflozin reduces hyperfiltration in subjects with type 1 diabetes.

On the other hand, a meta-analysis of sotagliflozin [17] has indicated an alternative impact on GFR. It was seen that investigations of under 24 weeks' period indicated improvement in GFR. Unfortunately after 28 weeks, an increment in GFR was seen. Therefore, there is a need for further investigation on sotagliflozin so we can comprehend its effect on GFR.

Microalbuminuria is an early marker of diabetic nephropathy. A meta-analysis of sotagliflozin has shown a decrease in albumin to creatinine ratio. Decreased albumin levels in diabetic patients give us further proof of the protection that SGTL2 inhibitors provide to kidneys.

Hence, it can be said that SGLT2 inhibitors can have protective effects on kidneys: they decrease microalbuminuria and GFR, but the effects on GFR have to be further explored.

Fanconi Syndrome

Fanconi syndrome is a type of renal tubular acidosis, which can be caused by medications. Only one such case was reported after SGLT2 inhibitor use [24]. The patient improved substantially after discontinuation of canagliflozin and after he was hydrated with IV fluids and given subcutaneous insulin and IV potassium phosphate.

\section{Interpreting evidence and future recommendation}

It would be fair to conclude that SGLT2 inhibitors have far more benefits than risks. Their efficacy in controlling HBA1c, significant weight reduction, and their effect on improving arterial function cannot be underestimated. Their role in controlling hyperfiltration and significantly minimizing risks of several lifethreatening diseases is also of marked value. These drugs not only help reduce the weight gain secondary to insulin but also tend to reduce morbidity and mortality in the long run. The only significant risk factors are hypoglycemia and DKA. Most cases of hypoglycemia are mild and strict glucose monitoring by the patient can help to solve this problem. For diabetic ketoacidosis, proper doctor and patient education can reduce the risks substantially. The patients should know that in case of fatigue, vomiting, fever, or any presenting symptoms of DKA, their ketone level needs to be tested. However, this does lead us to question whether we have enough knowledge of how DKA caused by SGLT2 inhibitors presents. At which doses is it more likely to occur, which people are susceptible to it, and at which blood sugar level we should suspect DKA? A review needs to be done that can answer these vital questions so that this life-threatening condition can be diagnosed and managed effectively, and so that SGLT2 inhibitors, a groundbreaking discovery, can be prescribed widely, especially in patients with obesity and uncontrolled diabetes.

\section{Strengths and limitations}

This review provides a comprehensive overview of not only the safety and efficacy of SGLT2 inhibitors by including randomized control studies but also observational studies showing the benefits and risks of SGT2 inhibitors in type 1 diabetes. It highlights the role of SGLT2 inhibitors in type 1 diabetes. However, there are some limitations to the existing literature review: a collection of studies reported only in English, data obtained from only one database (PubMed), and randomized control trials on sotagliflozin were not included. The only research used is the meta-analysis of the effects of sotagliflozin.

\section{Conclusions}

Our analysis of the published literature concluded that SGLT2 inhibitors' use in type 1 diabetics is associated with more benefits than risks. The typical treatment of type 1 diabetes involves insulin therapy, however, tight glycemic control is very important to prevent microvascular and macrovascular complications. Treatment with insulin could potentially lead to unavoidable hypoglycemic episodes that can prove fatal. Since SGLT2 inhibitors' use is beneficial for type 2 diabetics, its use in type 1 diabetes is also a topic of great interest. Our study has shown that good glucose control, reduction in HBA1c, and weight and blood pressure reduction can not only reduce the anxiety of reaching treatment milestones in type 1 diabetics, but can also prevent major cardiovascular events. Other benefits such as increasing arterial efficacy and improving 
kidney hyperfiltration have the amazing prospect of improving the overall prognosis of chronically-ill diabetes patients. At the same time, the adverse effects of the drug cannot be overlooked, e.g., UTI, genital infections, hypoglycemia, and DKA. These side effects are modest except for DKA, which may prove to be fatal. But this can be prevented by counseling the patient, educational training to physicians about euglycemic DKA, regular check-ups, and recognition of any symptoms that point towards DKA. With proper care, these medications can be used widely and effectively for patients with DKA. However, deeper and more detailed studies need to be carried out to understand the use of these drugs further in type 1 diabetes patients, with concentrated efforts toward collecting information about SGLT2 inhibitors in DKA.

\section{Additional Information}

\section{Disclosures}

Conflicts of interest: In compliance with the ICMJE uniform disclosure form, all authors declare the following: Payment/services info: All authors have declared that no financial support was received from any organization for the submitted work. Financial relationships: All authors have declared that they have no financial relationships at present or within the previous three years with any organizations that might have an interest in the submitted work. Other relationships: All authors have declared that there are no other relationships or activities that could appear to have influenced the submitted work.

\section{References}

1. Management of blood glucose in adults with type 1 diabetes mellitus . (2020). Accessed: 15/7/2020: https://www.uptodate.com/contents/management-of-blood-glucose-in-adults-with-type-1-diabetesmellitus.

2. Fattah H, Vallon, V: The potential role of SGLT2 inhibitors in the treatment of type 1 diabetes mellitus . Drugs. 2018, 78:717-726. 10.1007/s40265-018-0901-y

3. Type 1 diabetes. (2019). Accessed: 26/7/2020: https://www.webmd.com/diabetes/type-1-diabetes.

4. Chen J, Fan F, Wang JY, Long Y, Gao CL, Stanton RC, Xu Y: The efficacy and safety of SGLT2 inhibitors for adjunctive treatment of type 1 diabetes: a systematic review and meta-analysis. Sci Rep. 2017, 9:44128. 10.1038/srep44128

5. Riddle MC, Cefalu WT: SGLT inhibitors for type 1 diabetes: an obvious choice or too good to be true? . Diabetes Care. 2018, 41:2444-2447. 10.2337/dci18-0041

6. Khunti K, Davies M, Majeed A, Thorsted BL, Wolden ML, Paul SK: Hypoglycemia and risk of cardiovascular disease and all-cause mortality in insulin-treated people with type 1 and type 2 diabetes: a cohort study. Diabetes Care. 2015, 38:316-322. https://doi.org/10.2337/dc14-0920

7. Patoulias D, Imprialos K, Stavropoulos K, Athyros V, Doumas M: SGLT-2 inhibitors in type 1 diabetes mellitus: a comprehensive review of the literature. Curr Clin Pharmacol. 2018, 13:261-272. 10.2174/1574884713666180807150509

8. Li K, Xu G: Safety and efficacy of sodium-glucose co-transporter 2 inhibitors combined with insulin in adults with type 1 diabetes: a meta-analysis of randomized controlled trials. J Diabetes. 2019, 11:645-655. 10.1111/1753-0407.12890

9. Mudaliar S, Armstrong DA, Mavian AA, et al.: Remogliflozin etabonate, a selective inhibitor of the sodiumglucose transporter 2, improves serum glucose profiles in type 1 diabetes. Diabetes Care. 2012, 35:21982200. https://doi.org/10.2337/dc12-0508

10. Perkins BA, Cherney DZ, Partridge H, et al.: Sodium-glucose cotransporter 2 inhibition and glycemic control in type 1 diabetes: results of an 8-week open-label proof-of-concept trial. Diabetes Care. 2014, 37:14801483. https://doi.org/10.2337/dc13-2338

11. Henry RR, Rosenstock J, Edelman S, et al.: Exploring the potential of the SGLT2 inhibitor dapagliflozin in type 1 diabetes: a randomized, double-blind, placebo-controlled pilot study. Diabetes Care. 2015, 38:412419. https://doi.org/10.2337/dc13-2955

12. Pieber TR, Famulla S, Eilbracht J, et al.: Empagliflozin as adjunct to insulin in patients with type 1 diabetes: a 4-week, randomized, placebo-controlled trial (EASE-1). Diabetes Obes Metab. 2015, 17:928-935. 10.1111/dom.12494

13. Tamez HE, Tamez AL, Garza LA, Hernandez MI, Polanco AC: Dapagliflozin as an adjunct therapy to insulin in the treatment of patients with type 1 diabetes mellitus. J Diabetes Metab Disord. 2015 Oct 9., 14:78. 10.1186/s40200-015-0210-X

14. Henry RR, Thakkar P, Tong C, Polidori D, Alba M: Efficacy and safety of canagliflozin, a sodium-glucose cotransporter 2 inhibitor, as add-on to insulin in patients with type 1 diabetes. Diabetes Care. 2015 , 38:2258-2265. 10.2337/dc15-1730

15. Dandona P, Mathieu C, Phillip M, et al.: Efficacy and safety of dapagliflozin in patients with inadequately controlled type 1 diabetes: the DEPICT-1-1 52-week study. Diabetes Care. 2018, 41:2552-2559. 10.2337/dc18-1087

16. Kaku K, Isaka H, Toyoshima J, Sakatini T: Clinical pharmacology study of ipragliflozin in Japanese patients with type 1 diabetes mellitus: a phase 2, randomized, placebo-controlled trial. Diabetes Obes Metab. 2019, 21:1445-1454. 10.1111/dom.13679

17. Musso G, Gambino R, Cassader M, Paschetta E: Efficacy and safety of dual SGLT $1 / 2$ inhibitor sotagliflozin in type 1 diabetes: meta-analysis of randomised controlled trials. BMJ. 2019, 365:11328. 10.1136/bmj.11328

18. Mathieu C, Rudofsky G, Phillip M, et al.: Long-term efficacy and safety of dapagliflozin in patients with inadequately controlled type 1 diabetes (the DEPICT-2 study): 52-week results from a randomized controlled trial. Diabetes Obes Metab. 2020, 22:1516-1526. https://doi.org/10.1111/dom.14060

19. Lunder M, Janić M, Japelj M, Juretič A, Janež A, Šabovič M: Empagliflozin on top of metformin treatment improves arterial function in patients with type 1 diabetes mellitus. Cardiovasc Diabetol. 2018, 17:153. 


\section{Cureus}

10.1186/s12933-018-0797-6

20. Cherney DZ, Perkins BA, Soleymanlou N, et al.: Renal hemodynamic effect of sodium-glucose cotransporter 2 inhibition in patients with type 1 diabetes mellitus. Circulation. 2014, 129:587-597.

10.1161/CIRCULATIONAHA.113.005081

21. Peters AL, Buschur EO, Buse JB, Cohan P, Diner JC and Hirsch IB: Euglycemic diabetic ketoacidosis: a potential complication of treatment with sodium-glucose cotransporter 2 inhibition. Diabetes Care. 2015, 38:1687-1693. 10.2337/dc15-0843

22. Tahir H, Wani A, Daruwalla V, Daboul N, Sagi J: Euglycemic diabetic ketoacidosis and severe acute kidney injury secondary to off label use of sodium glucose cotransporter- 2 inhibitor in a type-1 diabetic patient. J Ayub Med Coll Abbottabad. 2015, 27:923-924.

23. Markey AG, Scott TA, Killen JC, Venter JA: Sodium-glucose co-transporter 2 inhibitors: think twice about diabetic ketoacidosis. Aust J Gen Pract. 2018, 47:223-225. 10.31128/AFP-09-17-4348

24. Khan N, Tso K, Broussard J, Dziuba M: Canagliflozin-induced Fanconi syndrome in a patient with previously unrecognized type 1 diabetes. Am J Health Syst Pharm. 2019, 76:1930-1933. 10.1093/ajhp/zxz226

25. Riddle MC, Cefalu WT: SGLT inhibitors for type 1 diabetes: an obvious choice or too good to be true? . Diabetes Care. 2018, 41:2444-2447. 10.2337/dci18-0041

26. Bonora BM, Avogaro A, Fadini GP: Sodium-glucose co-transporter-2 inhibitors and diabetic ketoacidosis: an updated review of the literature. Diabetes Obes Metab. 2018, 20:25-33. 10.1111/dom.13012

27. Taylor SI, Blau JE, Rother KI, Beitelshees AL: SGLT2 inhibitors as adjunctive therapy for type 1 diabetes: balancing benefits and risks. Lancet Diabetes Endocrinol. 2019, 7:949-958. doi:10.1016/S22138587(19)30154-8 